\title{
Switching Costs and Information Technology: The Case of IT Outsourcing
}

\author{
Christian Peukert* \\ Institute of Economic Policy \\ Ludwig Erhard Chair \\ Ulm University, Germany
}

August 9, 2010

\begin{abstract}
A large panel of micro data from US credit unions for the years 1999 to 2009 reveals that with more than 98 percent, outsourcing has been by far the preferred mode of IT provision in the recent years. However, the average credit union only sticks with the same vendor for four years.

This paper empirically investigates determinants of the decision to switch suppliers. Moreover we provide evidence for the existence and magnitude of switching costs. The estimates suggest that average switching costs account for three percent of annual expense.
\end{abstract}

Keywords: Outsourcing, ICT, IT, IS, switching costs, lock-in, US credit unions JEL No.: L24, L11, G21

*Preliminary version. The paper is accepted for presentation at INFORMS Annual meeting, November 2010, Austin, Texas, United States. I would like to thank Werner Smolny, Daniel Siepe and participants of the 8th ZEW Conference on the Economics of ICT, Mannheim, Germany, July 2010 for helpful comments on an earlier version. I am especially grateful to Daniel Cerquera, Ludivine Martin, Michael Ward and Aoife Hanley. All errors are mine. Contact details: christian.peukert@uni-ulm.de, Helmholtzstr. 20, D-89081 Ulm, Tel: +49 7315024265. 


\section{Introduction}

Outsourcing, or division of labor, has gained much attention during the last decades. Both in management and economics, scholars have made efforts to shed light on the determinants of make-or-buy-decisions and the resulting effects on firms and economies. A particular body of the literature emphasizes the problem of (re)contracting a supplier. When changing the supplier means that investments specific to the current supplier have to be duplicated, switching costs occur (Farrell and Klemperer, 2007, p. 1977). The literature has studied switching costs from a broad theoretical perspective (see the surveys by Farrell and Klemperer (2007) and Chen and Hitt (2006) for the particular case of information technology (IT)). Empirical studies provide evidence on switching costs in IT markets (Greenstein, 1993; Knittel, 1997; Chen and Hitt, 2002; Whitten and Wakefield, 2006; Krafft and Salies, 2008; Maicas et al., 2009), however the literature has not provided a direct estimate of switching costs so far.

In this paper, we focus on the specific case of IT outsourcing to study the effects of changing vendors. A rich data-set allows us to track US cooperative banks and their data processing vendors in the period of 1999-2009. Our methodology allows to target three issues: What are the determinants for switching, is there evidence for switching costs in IT Outsourcing, and if, what is their magnitude?

The remainder is structured as follows: Section 2 briefly introduces credit unions and their role in the US financial system. The data is discussed in section 3 followed by the derivation of the empirical model in section 4 . Results are presented in section 5 , section 6 concludes. 


\section{Background discussion}

Credit unions are non-profit member-owned financial cooperatives. Membership is based on a community, organizational, religious or employee affiliation (Branch and Grace, 2008). In 2008 US credit unions (CUs) had nearly 90 million members which accounts for roughly 44 percent of the economically active population. Approximately 8,000 CUs held some $\$ 692$ billion in deposits which accounts for about 10 percent of total deposits in the US. ${ }^{1}$

IT has been playing an important role in the financial sector since the 1950s with applications such as check handling, bookkeeping, credit analysis, automated teller machine (ATM) and e-banking (Franke, 1987). In order to capitalize on economies of scale and gain access to technology and expertise, organizations do not operate own data centers but choose to resort to external suppliers of IT services (Loh and Venkatraman, 1992). CUs rely particularly on IT Outsourcing for essential technology services like processing of deposit and loan data, costumer information files, and general ledger processing (Robbins and Van Walleghem, 2004). Case study research in the US, Europe and Australia has shown that the majority of IT Outsourcing contracts has a duration of less than eight years (Lacity and Willcocks, 2001, p. 150). Hence organizations are regularly confronted with the decision to renew an existing contract or evaluate the market and switch vendors. However, the literature has shown that switching is associated with costs. Based on Klemperer's (1995) categorization of switching costs, Chen and Hitt (2006) point to the specifics of IT. Issues such as complementary investments (e.g. employees training), network effects and compatibility may specifically lead to switching costs in the case of IT Outsourcing. Empirical studies provide evidence that compatibility between the client's installed base and the new system

\footnotetext{
${ }^{1}$ Figures are calculated using data from World Council of Credit Unions (WCCU) and Federal Deposit Insurance Corporation (FDIC).
} 
influences the vendor choice and having bought from one supplier increases the likelihood to buy from the same supplier again (Greenstein, 1993; Shapiro and Varian, 1999; Chen and Hitt, 2002). Ono and Stango (2005) (using the same dataset as in this paper) study vendor choice in a random utility framework. In a second stage, they find that there is unobserved correlation between the utility from alternative vendors when investigating the decision of switching vendors in a the second stage. Ono and Stango (2005) conclude that this suggests evidence for switching costs. Our paper partly borrows from Ono and Stango (2005) and extends their work in two major aspects: first, we aim at directly estimating the size of switching costs; second, we extend the data to a period of 10 years to end up with a higher number of observed switches.

\section{Data}

A panel on US CUs collected by and publicly available from National Credit Union Administration (NCUA) is used for the empirical analysis. ${ }^{2}$ CUs are obligated to file quarterly Call Reports spanning a wide range of variables. Beside financial issues the data also provide information on the organization of information processing and the information processing vendor. The data has been used by other authors studying IT Outsourcing (Borzekowski and Cohen, 2005; Ono and Stango, 2005; Knittel and Stango, 2008; Weigelt and Sarkar, 2009), however this is the first paper to examine the size of switching costs.

The sample tracks 10423 CUs and 178 vendors in the period from December 1999 to December 2009 in a yearly frequency. Due to panel attrition the total number of observations is 69,638 . Figure 1 shows that the number of CUs decreased by nearly 30 percent during the observed period.

\footnotetext{
${ }^{2}$ See Table 7 in the appendix for a population-sample comparison based on data provided by Credit Union National Association (CUNA).
} 
Figure 1: Number of CUs

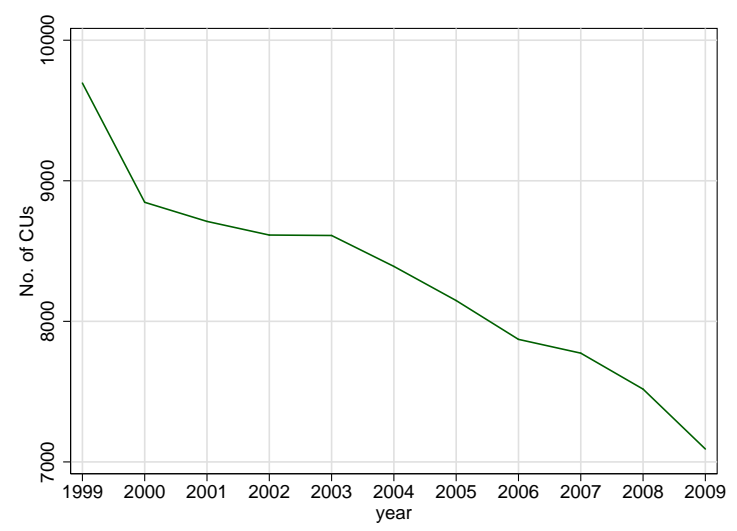

Source: NCUA, own illustration.
Figure 2: IT Outsourcing

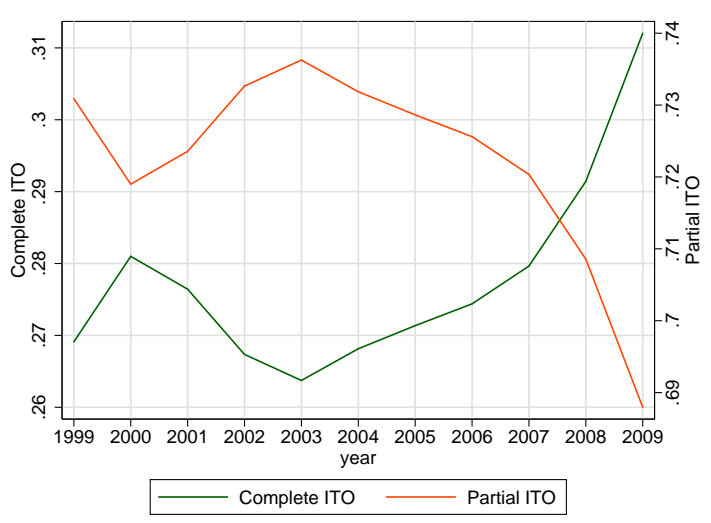

\subsection{IT Outsourcing}

The literature on IT Outsourcing finds that outsourcing is no "simple dichotomous decision" (Grover et al., 1996, p. 95) and thus suggests to distinguish between different types of sourcing decisions. Lacity et al. (2009) distinguish between complete ('total') and partial ('selective') IT Outsourcing. In the data CUs can indicate their IT system as either (1) manual (no automation), (2) vendor supplied in-house system, (3) vendor on-line service bureau, (4) CU developed in-house system, or (5) other. We treat (2) as partial outsourcing and (3) as complete outsourcing and include only those CUs indicating (2) or (3) in the sample. Note that this accounts for more than 98 percent of the initial observations, illustrating that IT Outsourcing is very common in the CU industry. Figure 2 shows that while partial IT Outsourcing is done by more than nearly three quarters of the CUs in the sample, there is a negative time trend. Accordingly, roughly one quarter has sourced out completely with a positive time trend. Descriptive statistics in Table 1 show that there are significant differences between the modes of outsourcing. ${ }^{3}$ Partial outsourcing is preferred by smaller firms, federal chartered and low-income designated CUs. Interestingly complete outsourcing is more common in rural areas ${ }_{3}^{3}$ See below for a detailed description of the variables referred to here. 
and at the same time the average number of electronic service offerings is higher. ${ }^{4}$ Vendor tenure (given in years) is significantly lower for partial outsourcing. We also find descriptive evidence that the percentage of vendor switches does not significantly vary across modes of outsourcing.

Table 1: Mean comparison: modes of outsourcing

\begin{tabular}{lrrrrrr}
\hline & \multicolumn{2}{c}{ Partial } & \multicolumn{2}{c}{ Complete } & \multicolumn{2}{c}{ Diff } \\
& mean & sd & mean & sd & mean & $t$ stat \\
\hline Expense growth & 0.070 & 0.200 & 0.067 & 0.152 & $0.004^{* * *}$ & $(2.84)$ \\
Vendor switch & 0.049 & 0.216 & 0.046 & 0.210 & -0.000 & $(-0.28)$ \\
Log Deposits & 16.136 & 1.977 & 16.702 & 1.175 & $-0.584^{* * *}$ & $(-41.46)$ \\
Log Deposits & 264.271 & 64.918 & 280.329 & 39.182 & $-16.657^{* * *}$ & $(-36.02)$ \\
Federal chartered & 0.624 & 0.484 & 0.577 & 0.494 & $0.051^{* * *}$ & $(13.15)$ \\
Low income & 0.101 & 0.302 & 0.088 & 0.283 & $0.012^{* * *}$ & $(5.44)$ \\
Urban area & 0.236 & 0.424 & 0.230 & 0.421 & $0.006^{*}$ & $(1.91)$ \\
Vendor tenure & 3.707 & 2.607 & 4.034 & 2.667 & $-0.281^{* * *}$ & $(-12.95)$ \\
Services difference & 0.445 & 4.078 & -0.428 & 4.225 & $0.861^{* * *}$ & $(25.03)$ \\
Maximum services & 0.024 & 0.154 & 0.033 & 0.180 & $-0.012^{* * *}$ & $(-4.27)$ \\
No. of services & 5.754 & 5.527 & 7.892 & 4.619 & $-2.113^{* * *}$ & $(-47.71)$ \\
Switches from vendor & 0.050 & 0.090 & 0.047 & 0.101 & $0.002^{* *}$ & $(2.14)$ \\
Switches to vendor & 0.049 & 0.077 & 0.049 & 0.085 & 0.000 & $(0.43)$ \\
Vendor M\&A & 0.267 & 0.443 & 0.199 & 0.399 & $0.083^{* * *}$ & $(24.98)$ \\
\hline Observations & 50100 & & 19538 & & 81578 & \\
\hline Nite
\end{tabular}

Note: $t$ statistics in parentheses. ${ }^{*} p<0.10,{ }^{* *} p<0.05,{ }^{* * *} p<0.01$

Source: NCUA, own calculations.

\subsection{Vendors and vendor switching}

Suppliers are identified by the name of the primary information processing vendor in our sample. The variable has been corrected for misspellings or abbreviations by manual inspection, consulting the internet and using the built-in SOUNDEX function of STATA 11 (Knuth et al., 1977; StataCorp., 2009). Moreover, during the observed period the vendor market has been subject to mergers and acquisitions (M\&A) (see Table 11; cf. Currie, 2000). After considering M\&A and aggregating subsidiaries we observe a total of 178 vendors in the sample (see Table 10). In most cases CUs continued to report the acquired vendor for a period

${ }^{4}$ See Table 9 in the appendix for a description of CU services. Note that the data include variables on services starting from 2000. 
of one or two years after the acquisition. However we treat a CU as client of the acquirer with the year of acquisition. Descriptive statistics in Table 1 reveal that more than one third of partial outsourcers and about one fifth of complete outsourcers has experienced vendor consolidation during the last decade.

We construct a dummy variable vendor switch that equals to one if the name of the primary information processing vendor changed between period $t$ and period $t+1$. However, we do not consider it as a switch when CUs report the name of the acquiring vendor after the acquisition. ${ }^{5}$

Table 2: Number of switches

\begin{tabular}{rrrrrrr}
\hline & \multicolumn{3}{c}{ Partial outsourcing } & \multicolumn{3}{c}{ Complete outsourcing } \\
& No. & $\%$ & cum \% & No. & \% & cum \% \\
\hline 2000 & 411 & 13.54 & 13.54 & 136 & 11.54 & 11.54 \\
2001 & 466 & 15.35 & 28.89 & 157 & 13.32 & 24.85 \\
2002 & 406 & 13.37 & 42.26 & 124 & 10.52 & 35.37 \\
2003 & 316 & 10.41 & 52.67 & 97 & 8.23 & 43.60 \\
2004 & 335 & 11.03 & 63.70 & 119 & 10.09 & 53.69 \\
2005 & 335 & 11.03 & 74.74 & 120 & 10.18 & 63.87 \\
2006 & 245 & 8.07 & 82.81 & 107 & 9.08 & 72.94 \\
2007 & 214 & 7.05 & 89.86 & 144 & 12.21 & 85.16 \\
2008 & 171 & 5.63 & 95.49 & 85 & 7.21 & 92.37 \\
2009 & 137 & 4.51 & 100.00 & 90 & 7.63 & 100.00 \\
\hline Total & 3036 & 100.00 & & 1179 & 100.00 & \\
\hline
\end{tabular}

Source: NCUA, own calculations.

Table 2 and Figure 3 indicate that the number of switches fell over time. Interestingly, switching is far more common in partial outsourcing but the number of switches in 2009 is only 30 percent of 2000. Compared to that, the 2009 figure of switches with complete outsourcing is roughly 65 percent of the number of switches in 2000. Inspection of the plot for the number of CUs suggests however that this trend might be more due to a decrease of market size than due to

\footnotetext{
${ }^{5}$ Figure 10 in the appendix shows the percentage of switches and the number of vendors when switches due to acquisitions and switches between affiliates are not considered as a switch. The percentage of switches is much higher compared to the plots shown here. Moreover, the peak in 2004 might be explained by Fiserv Inc.'s \$320 million acquisition of EDS' Consumer Network Services in late 2002 (Muckian, 2002).
} 
Figure 3: Vendor switching (1)

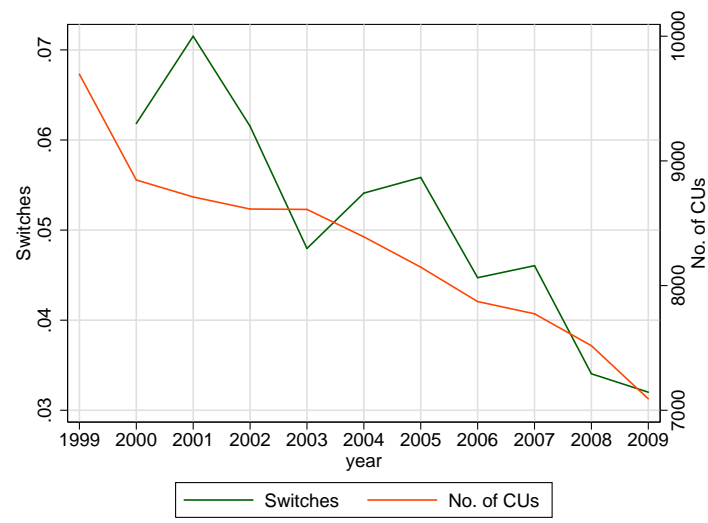

Source: NCUA, own illustration.

Figure 5: Vendor switching (3)

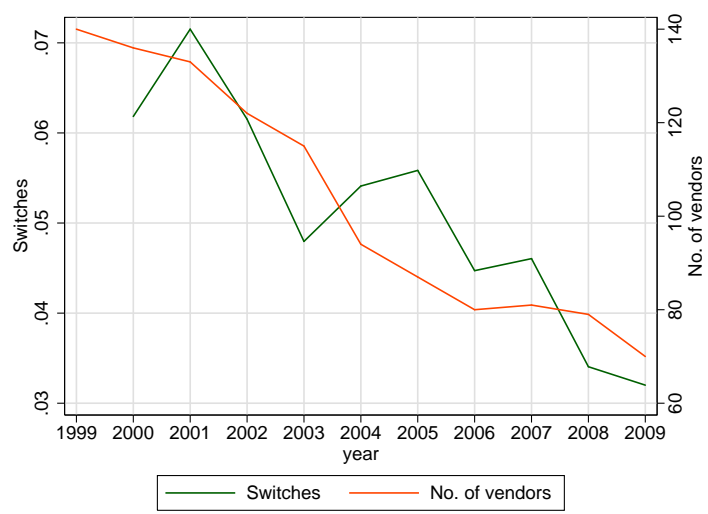

Source: NCUA, own illustration.
Figure 4: Vendor switching (2)

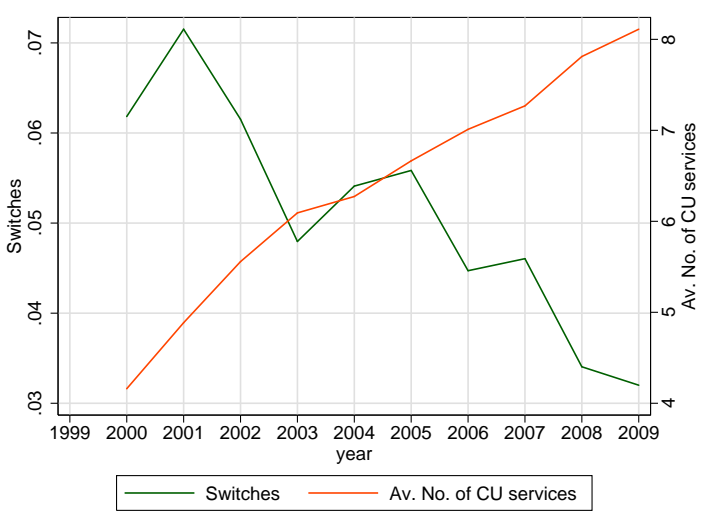

Figure 6: Vendor switching (4)

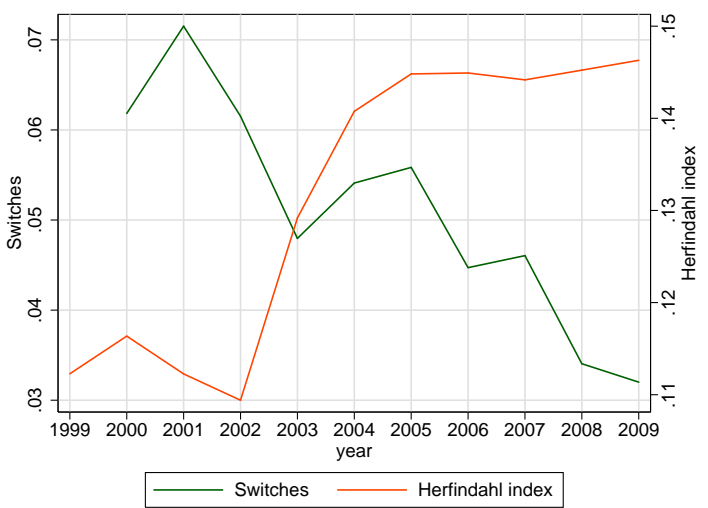

systematically less switching. ${ }^{6}$ Nevertheless, Figure 4 indicates that while switching became more rare, the average number of services offered by a CU rose by roughly 60 percent. A rising number of services might imply growing importance of complementary investments, network effects and compatibility and therefore an increase of switching costs.

Moreover, Figure 5 shows that also the number of vendors decreased over time. This additionally suggests that a decrease of market size (however on the supply side) may explain the decrease in switching. The plot of the Herfindahl index

${ }^{6}$ The main reason is consolidation in the $\mathrm{CU}$ market. We plan to extend out analysis to control for the effects of a declining CU market. 
indicating an increase in concentration in the vendor market in Figure 6 further strengthens this argument. It seems that less switching is accompanied by less competition in the vendor market.

The descriptive statistics in Table 3 draw a picture of what distinguishes switchers from non-switchers; switching firms are significantly smaller, more likely to be located in urban areas and offer less electronic services.

Table 3: Mean comparison: switching

\begin{tabular}{lrrrrrrr}
\hline & \multicolumn{2}{c}{ Non-switchers } & \multicolumn{2}{c}{ Switchers } & \multicolumn{2}{c}{ Diff } & \\
& mean & sd & mean & sd & & mean & $t$ stat \\
\hline Expense growth & 0.067 & 0.185 & 0.104 & 0.240 & $-0.034^{* * *}$ & $(-10.89)$ & \\
Log Deposits & 16.313 & 1.803 & 15.928 & 1.834 & $0.410^{* * *}$ & $(14.38)$ & \\
Log Deposits & 269.368 & 59.229 & 257.078 & 59.191 & $13.199^{* * *}$ & $(14.13)$ & \\
Federal chartered & 0.611 & 0.488 & 0.612 & 0.487 & -0.001 & $(-0.14)$ & \\
Low income & 0.097 & 0.297 & 0.101 & 0.302 & -0.001 & $(-0.20)$ & \\
Urban area & 0.233 & 0.423 & 0.257 & 0.437 & $-0.017^{* * *}$ & $(-2.52)$ \\
Vendor tenure & 3.855 & 2.615 & 2.693 & 2.656 & $1.149^{* * *}$ & $(26.51)$ \\
Services difference & 0.230 & 4.125 & -0.399 & 4.352 & $0.634^{* * *}$ & $(9.06)$ \\
Maximum services & 0.024 & 0.153 & 0.083 & 0.276 & $-0.102^{* * *}$ & $(-18.55)$ \\
No. of services & 6.431 & 5.369 & 4.825 & 5.250 & $1.684^{* * *}$ & $(18.51)$ \\
Switches from vendor & 0.042 & 0.066 & 0.187 & 0.269 & $-0.141^{* * *}$ & $(-95.60)$ \\
Switches to vendor & 0.044 & 0.061 & 0.145 & 0.216 & $-0.105^{* * *}$ & $(-78.21)$ \\
Vendor M\&A & 0.252 & 0.434 & 0.175 & 0.380 & $0.076^{* * *}$ & $(11.27)$ \\
Complete ITO & 0.281 & 0.450 & 0.269 & 0.443 & -0.002 & $(-0.28)$ \\
\hline Observations & 66281 & & 3357 & & 81578 & & \\
\hline
\end{tabular}

Note: $t$ statistics in parentheses. ${ }^{*} p<0.10,{ }^{* *} p<0.05,{ }^{* * *} p<0.01$

Source: NCUA, own calculations.

\subsection{Expenses}

Different types of expenses relevant for the empirical analysis are observed in the data. Expenses for office operations include in-house IT cost beside expenses for communications, stationery and supplies, liability insurance, bond insurance, furniture and equipment rental and/or maintenance and depreciation, and bank charges. Partial IT Outsourcing, defined as a vendor supplied in-house system, would hence be included in this variable.

Expenses for professional and outside services include outside IT servicing be- 
side legal fees, audit fees, accounting services, and consulting fees. Expense for complete IT Outsourcing, defined as vendor on-line service bureau, is to be found in this variable.

Both are given in dollars units and have been deflated using Producer Price Index (PPI) data provided by the US Bureau of Labor Statistics (BLS). ${ }^{7}$ In the empirical analysis, we use the sum of office operations expense and professional and outside service expense. Data inspection reveals extreme outliers on both ends, therefore the 1st and 99th percentile are dropped. Figure 7 shows an increase in average expenses over time. Plotting the growth rate however reveals fluctuations. Figure 8 indicates that the growth rate of expenses more or less follows the switching behavior with a one year lag. Nevertheless, switching seems to occur more frequently when the growth rate of expenses is relatively low. This may suggest that CUs switch vendors when the new vendor offers a lower price than the old vendor; we use this as a starting point for the derivation of the empirical model.

Figure 7: Expenses

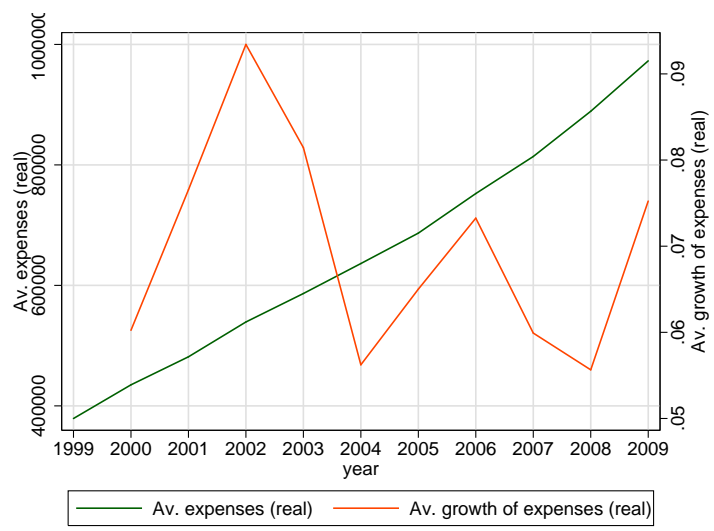

Source: NCUA, own illustration.
Figure 8: Vendor switching (5)

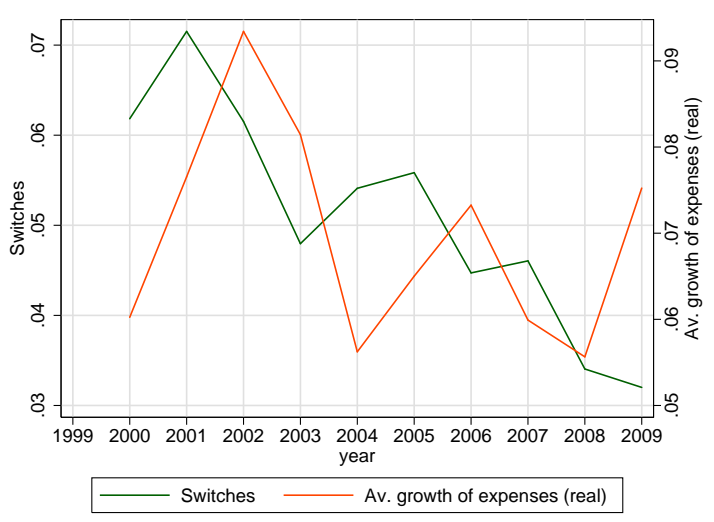

7 PPI data for the sector Professional and Technical Services was used. 


\section{Empirical analysis}

\subsection{Model derivation}

Our model is based on the approach of Elzinga and Mills (1998), where we assume a market with two vendors $A, B .{ }^{8}$ In period $t, \mathrm{CU} i$ contracts vendor $A$, at expense $P_{i, t}$. In period $t+1, \mathrm{CU} i$ can either continue to contract $A$ or switch to vendor $B$. Let $V_{i}^{*}$ denote the value to $\mathrm{CU} i$, such that

$$
V_{i, t+1}^{*}=a\left(\Delta P_{i}-S_{i, t}^{*}\right)
$$

where $a_{i}$ is a parameter, $\Delta P_{i}=P_{i, t+1}-P_{i, t}$ is the difference in expense on IT services of CU $i$ and $S_{i}^{*}$ is CU $i$ 's switching cost. ${ }^{9}$ To normalize we divide (1) by $P_{i, t}$, drop time indices and use lower case notation for convenience, which gives

$$
\begin{aligned}
& \frac{V_{i, t+1}^{*}}{P_{i, t}}=a\left(\frac{P_{i, t+1}-P_{i, t}}{P_{i, t}}-\frac{S_{i, t}^{*}}{P_{i, t}}\right) \\
& =v_{i}^{*}=a\left(\Delta p_{i}-s_{i}^{*}\right)
\end{aligned}
$$

where $\Delta p_{i}$ is the percentage change in expenses between $t$ and $t+1$. We maintain that $\mathrm{CU} i$ will switch vendors if $v_{i}^{*}>0$, hence the switching decision only depends on the difference of costs between vendors, adjusting for switching cost. Because $s_{i}^{*}$ is not observable, we assume that switching costs are a linear function of observable CU characteristics, such that

$$
s_{i}^{*}=\beta_{0}+\beta^{\prime} x_{i}+\varepsilon_{i}^{s}
$$

\footnotetext{
${ }_{8}$ An extension to $n$ vendors is similar to thinking of $A$ as the current vendor and $B$ as the set of the remaining $n-1$ vendors.

${ }^{9}$ Note that $S_{i}$ occurs regardless of whether CU $i$ switches or not. For the case that $\mathrm{CU} i$ does not switch vendors, think of switching cost as the cost of being locked-in: cost that prevent from switching. We discuss this issue in more detail below.
} 
where $x_{i}$ is a vector of $\mathrm{CU}$ characteristics, $\beta_{0}, \beta$ are coefficient vectors and $\varepsilon_{i}^{s}$ is an error term. In our data $P$ is not directly observed either, however, information on total expense on office operations and professional and outside services $C$ is available. Thus, we consider $\Delta p_{i}$ as a linear function of total cost and other expenses, with

$$
\Delta p_{i}=\Delta c_{i}-\gamma^{\prime} o_{i}-\varepsilon_{i}^{p}
$$

where $\gamma$ is a vector of coefficients, $o_{i}$ is a vector of characteristics leading to other expenses and $\varepsilon_{i}^{p}$ is an error term. Rewriting (3) and substituting (4) and (5) gives

$$
\Delta c_{i}=\alpha+\theta v_{i}^{*}+\beta^{\prime} x_{i}+\gamma^{\prime} o_{i}+\varepsilon_{i}
$$

when setting $\theta=a^{-1}, \alpha=\beta_{0}, \varepsilon_{i}=\varepsilon_{i}^{s}+\varepsilon_{i}^{p}$.

We treat $v_{i}^{*}$ as a latent variable that is indirectly observed according to the decision to switch vendors, i.e. according to the rule

$$
v_{i}= \begin{cases}1, & \text { if } v_{i}^{*}>0 \\ 0, & \text { otherwise }\end{cases}
$$

This gives a final model in the general class of simultaneous equations with dummy endogenous variables (Heckman, 1978; Maddala, 1983, p. 120-122), with

$$
\begin{array}{r}
\Delta c_{i}=\alpha+\theta v_{i}+\beta^{\prime} x_{i}+\gamma^{\prime} o_{i}+\varepsilon_{i} \\
v_{i}^{*}=a+d^{\prime} w_{i}+\varepsilon_{i}^{v}
\end{array}
$$

where $\varepsilon_{i}$ and $\varepsilon_{i}^{v}$ are bivariate normal with mean zero and covariance matrix $\left(\begin{array}{ll}\sigma & \rho \\ \rho & 1\end{array}\right)$, $w_{i}$ is vector of exogenous covariates including $x_{i}$ and $z_{i}$, where $z_{i}$ is a vector of identifying variables with $d_{z} \neq 0$ and $\operatorname{Cov}\left(z_{i}, \varepsilon_{i}\right)=0$. 


\subsection{The size of switching costs}

Switching costs can be defined from two different perspectives. The first is an opportunity cost approach - switching costs are the costs that prevent the credit union from switching vendors (the cost of being locked-in, cf. Shapiro and Varian, 1999, p. 103 sq.). We refer to this as indirect switching costs. The second is the actual expense a credit union is faced with after switching vendors (the cost of substitution, cf. von Weizsäcker, 1984). We refer to this as the direct switching cost. Combining both, we have to derive an estimate for

$$
\begin{aligned}
s_{i} & =v_{i} E\left(s_{i}^{*} \mid v_{i}=1\right)+\left(1-v_{i}\right) E\left(s_{i}^{*} \mid v_{i}=0\right) \\
& =v_{i}\left[E\left(s_{i}^{*} \mid v_{i}=1\right)-E\left(s_{i}^{*} \mid v_{i}=0\right)\right]+E\left(s_{i}^{*} \mid v_{i}=0\right) .
\end{aligned}
$$

To see the derivation of the estimate $\hat{s_{i}}$ recall that according to (3) and (5) switching costs $s_{i}$ can be expressed as

$$
\begin{aligned}
& s_{i}^{*}=\Delta p_{i}-v_{i}^{*} \\
& s_{i}^{*}=\Delta c_{i}-\gamma^{\prime} o_{i}-v_{i}^{*}-\varepsilon_{i}^{p} .
\end{aligned}
$$

Separate (7), such that

$$
\begin{array}{r}
\left.s_{i}^{*}=\Delta c_{i}-\gamma^{\prime} o_{i}-\theta-\left(\varepsilon_{i}-\varepsilon_{i}^{s}\right) \quad \text { if } v_{i}^{*}>0 \text { (i.e., } \varepsilon_{i}^{v}<a+d^{\prime} w_{i}\right) \\
\left.s_{i}^{*}=\Delta c_{i}-\gamma^{\prime} o_{i}-\left(\varepsilon_{i}-\varepsilon_{i}^{s}\right) \quad \text { if } v_{i}^{*} \leq 0 \text { (i.e., } \varepsilon_{i}^{v} \geq a+d^{\prime} w_{i}\right)
\end{array}
$$

and

$$
\begin{aligned}
& E\left(s_{i}^{*} \mid v_{i}=1\right)=\Delta c_{i}-\gamma^{\prime} o_{i}-\theta-E\left(\varepsilon_{i}-\varepsilon_{i}^{s} \mid \varepsilon_{i}^{v}<a+d^{\prime} w_{i}\right) \\
& E\left(s_{i}^{*} \mid v_{i}=0\right)=\Delta c_{i}-\gamma^{\prime} o_{i}-E\left(\varepsilon_{i}-\varepsilon_{i}^{s} \mid \varepsilon_{i}^{v} \geq a+d^{\prime} w_{i}\right) .
\end{aligned}
$$


Then, from the truncated normal distribution (Maddala, 1983, p. 365 sq.) follows that $s_{i}$ as given in (8) can be expressed as

$$
s_{i}=\Delta c_{i}-\gamma^{\prime} o_{i}-\theta+\left(\sigma \rho-\sigma^{s} \rho^{s}\right)\left(\frac{\phi\left(a+d^{\prime} w_{i}\right)}{\Phi\left(a+d^{\prime} w_{i}\right)}-\frac{\phi\left(a+d^{\prime} w_{i}\right)}{1-\Phi\left(a+d^{\prime} w_{i}\right)}\right)
$$

where $\phi$ is the standard normal density and $\Phi$ is the standard normal cumulative distribution function. However, because $\sigma^{s}$ and $\rho^{s}$ cannot be observed or estimated, we have to assume that $\rho^{s}=0$. Hence, our estimate of $s_{i}$ is given by

$$
\hat{s_{i}}=\widehat{\Delta c_{i}}-\hat{\gamma}^{\prime} o_{i}-\hat{\theta}+\hat{\sigma} \hat{\rho}\left(\frac{\phi\left(\hat{a}+\hat{d}^{\prime} w_{i}\right)}{\Phi\left(\hat{a}+\hat{d}^{\prime} w_{i}\right)}-\frac{\phi\left(\hat{a}+\hat{d}^{\prime} w_{i}\right)}{1-\Phi\left(\hat{a}+\hat{d}^{\prime} w_{i}\right)}\right) .
$$

\subsection{Empirical specification}

Equation (7) is estimated using the maximum likelihood estimator of STATA 11's TREATREG command. The dependent variable is the growth rate of the sum of expenses for office operations and professional and outside services as given in (2). We estimate models for the full sample and the subsamples of partial and complete outsourcing and include year and vendor dummies.

The vector $x_{i}$ includes the following control variables, lagged for one period:

Deposits: The size of a CU might influence the size of switching costs as the complexity of IT systems may rise with size. Size is measured by the total amount of share and deposits in dollar units, deflated using Consumer Price Index (CPI) data provided by the BLS.

Federal chartered, low income: We control for the type of charter because of significant differences between federal and state-chartered CUs. For example, federal chartered CUs are exempt from all taxes, while states vary in their tax treatment of state-charted CUs. Moreover, to encourage the expansion of membership to 
low-income individuals and underserved areas, CUs that receive a low-income designation from NCUA are granted benefits that other CUs do not have (Bickley, 2005; Hillman, 2005). Both types of subsidies could also have an indirect effect on switching costs.

Urban area: Based on standard metropolitan statistical area (SMSA) codes, we control for differences between CUs operating in urban and rural areas. For example because of skills shortages, switching costs might be higher in rural areas. Vendor tenure: The number of years a $\mathrm{CU}$ is customer to a vendor may be correlated to the amount of asset specific investments which may lead to switching costs. Our variable counts the years of having contracted the same vendor in every period. Accordingly, it is set to zero in case of a switch. Note an issue: by the nature of our sample, our measure of tenure is truncated. Every CU "starts" with a value of zero because the years prior to 1999 are not observed.

$C U$ services: The type of services a CU offers to its customers might influence the size of switching costs. Hence we include dummies for each service shown in Table 9 in the appendix.

Services difference, maximum services: As Ono and Stango (2005) point out, not switching vendors may simply be more the result of a good client-supplier match than high switching costs. We follow their approach and construct two variables that measure the match between CU $i$ and its (current or new) vendor. ${ }^{10}$ Suppose a CU prefers a vendor whose capabilities are compatible with its electronic service offerings. For each vendor and type of outsourcing arrangement (partial vs. complete), we measure the median, as well as the maximum number of services for its CU customers. Because vendors tend to sell standardized solutions to be able to exploit economies of scale (Miozzo and Grimshaw, 2005), CU $i$ may choose

\footnotetext{
${ }^{10}$ Ono and Stango (2005) use information on product offerings, i.e. auto loans, fixed-rate mortgage loans, variable-rate mortgage loans, credit cards, home equity lines/loans, money market, share certificate, IRA/KEOGH accounts, and business loans. We choose electronic service offerings because we believe that with these variables the client-supplier-link is stronger.
} 
a vendor whose typical customers are similar to $\mathrm{CU} i$. We measure this as the difference between $\mathrm{CU} i$ 's number of offerings and the median (services difference). The dummy variable maximum services is equal to one if $\mathrm{CU} i$ offers a number of electronic services that is equal to the maximum offered by any of the vendor's CU clients. This may capture a propensity to switch vendors due to growth. As Ono and Stango (2005) put it, a common reason for vendor switching is that a CU "outgrows" its current vendor, often by expanding its offerings beyond the capabilities of the vendor.

The vector $o_{i}$ includes dummy variables to control for sources of other expenses in the dependent variable: ${ }^{11}$

Audit: We argue that a change in the type of audit the CU $i$ has had in the previous period ${ }^{12}$ may be suitable to control for the effect of audit fees and accounting services on expenses. ${ }^{13}$

Insurance: Analogously we control for expense on insurance. We include a dummy variable set to one if $\mathrm{CU} i$ 's additional insurance status (share/deposit insurance coverage in addition to the government backed insurance fund) changed relative to the previous period.

\footnotetext{
${ }^{11}$ Recall that these are communications, stationery and supplies, liability insurance, bond insurance, furniture and equipment rental and/or maintenance and depreciation, bank charges, legal fees, audit fees, accounting services, and consulting fees.

${ }^{12}$ These are (1) Supervisory Committee , (2) CPA w/o Opinion , (3) CPA with Opinion , (4) League Audit and (5) Outside Accountant before 2002, and (6) Financial statement audit performed by state licensed persons, (7) Balance sheet audit performed by state licensed persons, (8) Examinations of internal controls over call reporting performed by state licensed persons, (9) Supervisory Committee audit performed by state licensed persons, (10) Supervisory Committee audit performed by other external auditors, (11) Supervisory Committee audit performed by the supervisory committee or designated staff after 2002 (due to Sarbanes-Oxley Act of 2002). The dummy Audit group 1 is one if (2), (3) or (6)-(9), Audit group 2 is one if (4), (5) or (10), Audit group 3 is one if (1) or (11). Audit group 3 is the omitted category.

${ }^{13}$ Note that it is unlawful for audit firms to provide audit services and non-audit services (including bookkeeping and consulting services) to the same customer at the same time since 2002 (SarbanesOxley Act of 2002, Sec. 201). However we consider audit fees and accounting fees to be correlated: When accounting is more complex (and therefore costly), auditing should also be more complex (and therefore costly).
} 
We are aware that those two variables are only partially suitable to control for all other factors affecting expense growth. We plan to further investigate this issue of omitted variables in a later version of the paper.

The vector $z_{i}$ includes three instrumental variables:

Switches from vendor, switches to vendor: We use instruments to try to account for the effect of word of mouth in switching decisions. Because the literature finds that "potential spillovers that would reduce the costs associated with a given technology appear to take the form of credit unions sharing information about how to use each technology more efficiently" (Borzekowski and Cohen, 2005, p. 7). We include the percentage of CUs, located outside CU $i$ 's home county, that use the same type of outsourcing arrangement and have also switched from the same old vendor / to the same new vendor in the same year CU $i$ switched. ${ }^{14}$ These variables may measure the implicit quality of the old vendor. When a high percentage of CUs switching from the old vendor can be interpreted as a lack of match, or quality, then we expect a positive sign for switches from vendor. Analogously we also expect a positive sign for switches to vendor.

Vendor MEA: Based on anecdotal evidence we believe that CUs may switch vendors in response to ownership change because they are dissatisfied with the new management. ${ }^{15}$ If this is the case, these types of switches are likely to be uncorrelated with a change in expenses. Therefore we include a dummy variable that is equal to one if the current vendor was involved in any type of M\&A during the previous year.

\footnotetext{
${ }^{14}$ Table 8 in the appendix lists the Top 3 switches in each year.

${ }^{15}$ See for example the webblog posting entitled "Data Processor: in the wake of ownership change" at http://chelseesbeat.wordpress.com/2009/10/23/ data-processor-in-the-wake-of-ownership-change/.
} 


\section{Results}

The presentation of the results is structured according to the three questions we attempt to answer: First, we discuss the results of the first-stage regression in order to shed light on the determinants of vendor switching. Second, we investigate the second-stage results where we show that switching vendors is associated with costs. Last, we present estimates on the size of switching costs in the CU market.

\subsection{Determinants of switching}

The second row of Table 4 shows the results for the first-stage regression. We find a non-linear relationship between size and the propensity to switch vendors in all specifications. The signs of Log Deposits and Log Deposits ${ }^{2}$ suggest that medium-sized CUs have the lowest probability of switching their partial outsourcing supplier. However in the complete outsourcing subsample, the opposite is true: here we find that the propensity to switch increases with size, but with decreasing returns to scale. In the partial subsample federal chartered CUs have a significantly higher probability to switch compared to state-chartered CUs. For complete outsourcers we do not find a significant effect of charter-type. Participation in the low-income program does not affect the switching decision as well. Location in an urban area does only have an effect on switching for partial outsourcers: those CUs have a higher propensity to switch. With each year of contracting the same vendor, the probability to switch decreases - in the partial subsample, as well as in the full sample. The fact that vendor tenure is insignificant suggests that the specificity of supplied services in a complete outsourcing setting is lower than in the partial setting; or put differently, supplied services are more standardized.

Our findings on Service difference are somehow puzzling. The positive sign in the subsample estimation for complete outsourcing suggest that a CU is more likely to 
Table 4: Estimation results

\begin{tabular}{|c|c|c|c|c|c|c|}
\hline \multirow[b]{2}{*}{ Expense growth } & \multicolumn{2}{|c|}{ Partial } & \multicolumn{2}{|c|}{ Complete } & \multicolumn{2}{|c|}{ All } \\
\hline & & & & & & \\
\hline Vendor switch & $0.0277^{* * *}$ & $(3.33)$ & $0.0557^{* * *}$ & $(5.12)$ & $0.0359^{* * *}$ & $(5.44)$ \\
\hline Log Deposits & $0.0197^{* * *}$ & $(2.89)$ & -0.0122 & $(-0.71)$ & $0.0182^{* * *}$ & $(3.09)$ \\
\hline Log Deposits ${ }^{2}$ & -0.0003 & $(-1.45)$ & 0.0006 & $(1.15)$ & -0.0003 & $(-1.54)$ \\
\hline Federal chartered & 0.0003 & $(0.16)$ & 0.0008 & $(0.36)$ & 0.0004 & $(0.24)$ \\
\hline Low income & $0.0182^{* * *}$ & $(5.77)$ & $0.0107^{* * *}$ & $(2.62)$ & $0.0164^{* * *}$ & $(6.46)$ \\
\hline Urban area & $0.0105^{* * *}$ & $(4.76)$ & $0.0047^{*}$ & (1.69) & $0.0089^{* * *}$ & $(5.04)$ \\
\hline Vendor tenure & $-0.0010^{* *}$ & $(-2.21)$ & 0.0004 & $(0.65)$ & $-0.0007^{*}$ & $(-1.88)$ \\
\hline Services difference & $0.0012^{* * *}$ & $(3.28)$ & $0.0024^{* * *}$ & $(3.66)$ & $0.0014^{* * *}$ & $(4.72)$ \\
\hline Maximum services & -0.0003 & $(-0.04)$ & $-0.0110^{*}$ & $(-1.67)$ & -0.0033 & $(-0.68)$ \\
\hline Audit & $0.0194^{* * *}$ & $(7.95)$ & $0.0057^{*}$ & $(1.84)$ & $0.0159^{* * *}$ & $(8.09)$ \\
\hline Insurance & $0.0228^{* * *}$ & $(3.08)$ & $0.0421^{* * *}$ & $(3.91)$ & $0.0270^{* * *}$ & $(4.39)$ \\
\hline Constant & $-0.2556^{*}$ & $(-1.69)$ & 0.1297 & $(0.90)$ & $-0.2430^{*}$ & $(-1.73)$ \\
\hline \multicolumn{7}{|l|}{ Vendor switch } \\
\hline Log Deposits & $-0.2993^{* * *}$ & $(-3.75)$ & $1.0162^{* * *}$ & $(3.43)$ & $-0.1725^{* *}$ & $(-2.35)$ \\
\hline Log Deposits ${ }^{2}$ & $0.0092^{* * *}$ & $(3.70)$ & $-0.0288^{* * *}$ & $(-3.24)$ & $0.0055^{* *}$ & $(2.41)$ \\
\hline Federal chartered & $0.0593^{* *}$ & $(2.52)$ & -0.0196 & $(-0.51)$ & $0.0363^{*}$ & $(1.83)$ \\
\hline Low income & -0.0242 & $(-0.64)$ & 0.0479 & $(0.72)$ & -0.0085 & $(-0.26)$ \\
\hline Urban area & $0.0599^{* *}$ & $(2.29)$ & -0.0509 & $(-1.10)$ & 0.0340 & $(1.52)$ \\
\hline Vendor tenure & $-0.0568^{* * *}$ & $(-10.63)$ & 0.0089 & $(1.02)$ & $-0.0416^{* * *}$ & $(-9.34)$ \\
\hline Services difference & $-0.0191^{* * *}$ & $(-4.78)$ & $0.0627^{* * *}$ & (7.23) & $-0.0071^{* *}$ & $(-2.05)$ \\
\hline Maximum services & $0.2241^{* * *}$ & (3.64) & 0.0237 & $(0.27)$ & $0.1746^{* * *}$ & (3.55) \\
\hline Switches from vendor & $2.9234^{* * *}$ & $(32.35)$ & $2.7463^{* * *}$ & $(22.80)$ & $2.8011^{* * *}$ & $(40.91)$ \\
\hline Switches to vendor & $1.1493^{* * *}$ & $(8.83)$ & $1.1999^{* * *}$ & $(7.18)$ & $1.4527^{* * *}$ & (15.81) \\
\hline Vendor M\&A & $-0.1257^{* * *}$ & $(-3.82)$ & -0.0419 & $(-0.77)$ & $-0.0974^{* * *}$ & $(-3.54)$ \\
\hline Constant & 7.5418 & $(0.00)$ & $-10.8083^{* * *}$ & $(-4.34)$ & 5.8871 & $(0.00)$ \\
\hline Yea & Yes & & Yes & & Yes & \\
\hline Vendor dummi & Yes & & Yes & & Yes & \\
\hline Service dummies & Yes & & Yes & & Yes & \\
\hline Log likelihood & $2.3 e+03$ & & $6.6 \mathrm{e}+03$ & & $7.6 e+03$ & \\
\hline$x^{2}$ & 605.8688 & & 469.8720 & & 891.0770 & \\
\hline $\mathrm{p}$-value $\rho=0$ & 0.3664 & & 0.1062 & & 0.9504 & \\
\hline$\rho$ & 0.0170 & & -0.0554 & & 0.0010 & \\
\hline$\sigma$ & 0.1987 & & 0.1499 & & 0.1864 & \\
\hline Observations & 50100 & & 19538 & & 69638 & \\
\hline
\end{tabular}

Note: $t, z$ statistics in parentheses, ${ }^{*} p<0.10,{ }^{* *} p<0.05,{ }^{* * *} p<0.01$.

All variables except audit, insurance, switches from vendor and switches to vendor are lagged by one period. Audit and insurance reflect changes between subsequent periods, switches from vendor and switches to vendor refer to the same period as vendor switch.

Tests: $p$-values in parentheses: Wald-Test for joint-significance of instruments in the first stage: partial $\chi^{2}=1291.48(0.000)$, complete $\chi^{2}=616.45(0.000)$, all $\chi^{2}=616.45(0.000)$. For each specification, a likelihood ratio test with the null of overidentification (valid instruments) cannot be rejected. Likelihood ratio test for no differences between partial and complete models: $\chi^{2}=2522.36(0.000)$.

Source: NCUA, own calculations. 
switch when its electronic service offerings deviate from that of its vendors typical customer. However for partial outsourcers the sign of the coefficient is negative. This may again suggest that vendor supplied in-house-systems are more specific and in turn a larger deviation from the "industry standard" lowers the probability to switch vendors. For Maximum services we find the expected signs; if a CU offers the maximum number of services in the vendor's client base, the propensity to switch is higher. This may support the hypothesis of a growth barrier associated with the current vendor. Anyhow it should be mentioned that the coefficient is not significantly different from zero in the complete outsourcing subsample.

Concerning our instrumental variables (Switches from vendor, Switches to vendor and Vendor $M \mathcal{E} A$ ) we can reject the null hypothesis of coefficients being jointly zero. Each has the expected sign. In the complete subsample however a change of ownership does not significantly affect the propensity to switch.

To summarize, we find that CU characteristics such as size, type of charter, geographical location and the supplier-client-match have effects on the decision to switch vendors. For CUs that use the complete mode of outsourcing, those characteristics are less influential compared to the those choosing a vendor-supplied in-house system.

\subsection{Is switching costly?}

In order to investigate our second question, we refer to the second-stage results presented in the top row of Table 4. The estimated coefficient of vendor switch is significantly positive in all specifications. This has two implications: First, switching vendors is costly. Second, switching vendors seems to be associated with a higher growth rate of expenses. We find a linear relation between size and expense growth for partial outsourcing and the full sample. The positive sign of Log Deposits implies that big CUs experience higher rates of expense growth. For 
complete outsourcing we do not find a significant size effect. Also there seems to be no significant difference between types of charters. Low income and Urban area are significantly positive in all specifications.

Interestingly, the impact of Vendor tenure seems to be negative for the case of partial outsourcing. The longer the relationship between supplier and client the higher the potential to cut cost. The positive sign of Service difference may imply that those CUs with less service offerings than the vendor's median client are faced with a higher growth in expenditure. We believe that this is an indirect effect: CUs with less electronic service offerings may be those with outdated technologies that may also operate below the median in terms of efficiency.

Our interpretation of the negative sign of Maximum services points in the same direction. Those CUs operating at the vendor's frontier may be those that also run business more efficient. However, the coefficient is only significant in the complete outsourcing subsample.

Audit and Insurance have the expected signs. A change in the type of audit seems to be positively correlated with growth in expense.

To sum up, we find that switching vendors has a significantly positive effect on growth of expenditure. We interpret this as evidence for switching costs. We also find that the influence of CU characteristics such as size, type of charter, geographical location and the supplier-client-match have different effects depending on the mode of outsourcing. A chow-type test with the null hypothesis of no differences between partial and complete models can be rejected at any significance level $\left(\chi^{2}=2522.36\right)$. 


\subsection{How costly is switching?}

The third question targets the size of switching costs. Our calculations according to equation (13) in Table 5 again reveal significant differences across modes of outsourcing. Concerning the full sample, average switching costs are about 3 percent of annual expense on professional and outside services and office operations. The estimate for partial outsources is even higher with about 4.5 percent. Interestingly, average switching costs for complete outsourcing are negative. This finding may be less surprising if we recall that Table 4 shows that for complete outsourcers both the decision to switch and growth of expense are relatively insensitive to the observed CU characteristics. Our estimate of switching costs is driven by those coefficients to a large extend. On the one hand this may imply a problem with omitted variables. On the other hand, again this might be due to more standardized, less individualized IT services which lower the need to duplicate specific investments when switching vendors.

Table 5: Size of switching cost

\begin{tabular}{lccccc}
\hline & & & & & \\
& mean & median & sd & $\min$ & $\max$ \\
\hline Partial & 0.0459 & 0.0239 & 0.1998 & -0.5603 & 1.3957 \\
Complete & -0.0090 & -0.0281 & 0.1521 & -0.5800 & 1.3331 \\
All & 0.0304 & 0.0093 & 0.1875 & -0.5765 & 1.3807 \\
\hline
\end{tabular}

Note: Significant at the one percent level $(t=51.47),(t=-8.31),(t=42.82)$.

Source: NCUA, BLS, own calculations.

Figure 9 depicts the percentage of switches and estimated switching costs over time. It illustrates that average switching costs are low when the percentage of CUs switching is low and high when relatively few switches occur, respectively. The histograms illustrate the variance across CUs.

Decomposing the estimates into switchers and non-switchers allows to paint a clearer picture. Table 6 shows that there are significant differences between the 
switching costs of switchers and non-switchers. This suggests evidence for the distinction between direct and indirect switching costs we made above. We find that direct costs are significantly larger than indirect costs and positive. Moreover, the estimate of mean negative switching costs for complete outsourcing seems to be largely driven by indirect switching costs.

Figure 9: Switching costs: partial vs. complete outsourcing
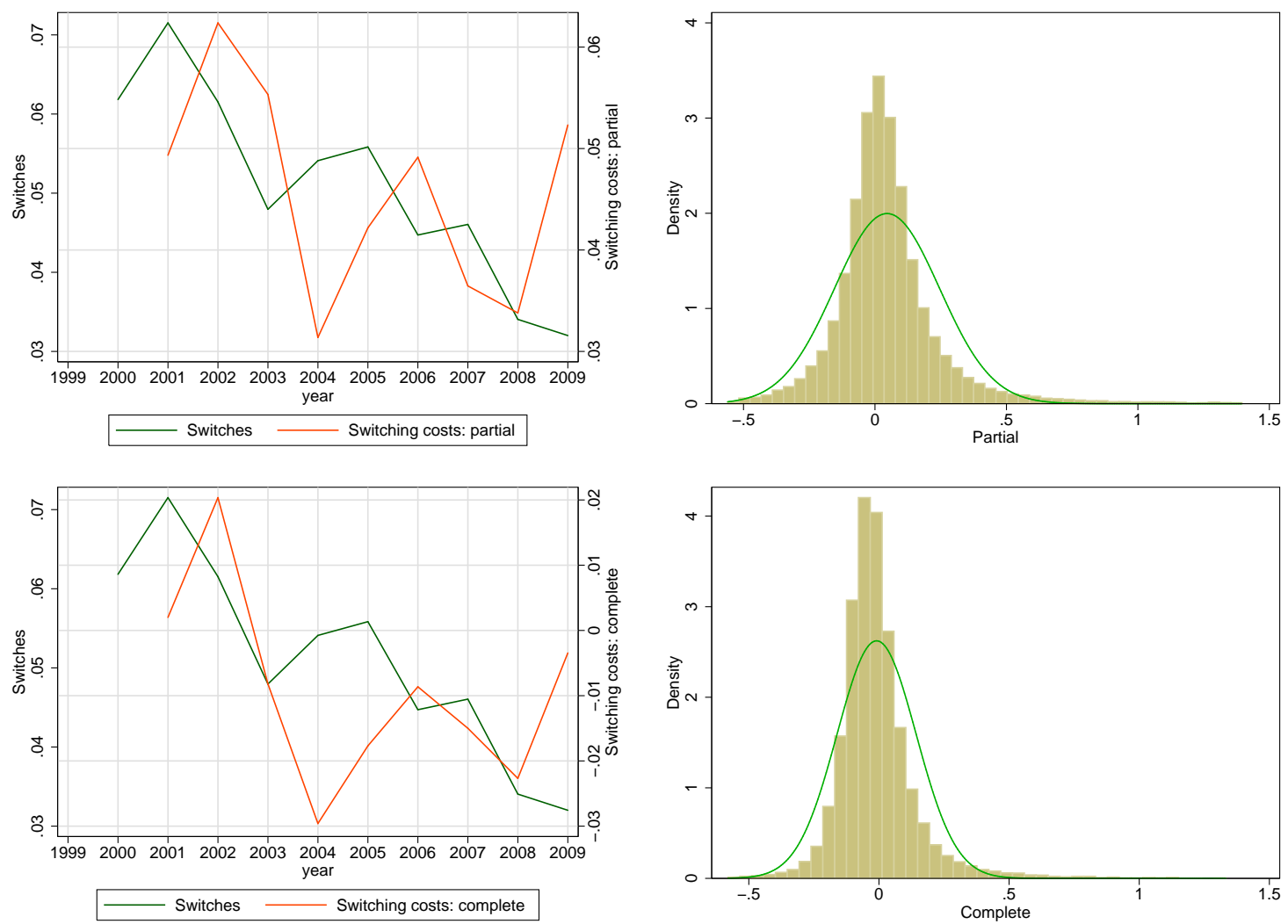

Note: Graphics refer to estimations based on coefficients reported in Table 4.

Source: NCUA, BLS, own illustration.

Table 6: Mean comparison: switching costs conditional on modes of outsourcing

\begin{tabular}{lrrrrrr}
\hline & \multicolumn{2}{c}{ Non-switchers } & \multicolumn{2}{c}{ Switchers } & \multicolumn{2}{c}{ Diff } \\
& mean & sd & mean & sd & diff & $t$ stat \\
\hline Partial & 0.0445 & 0.1966 & 0.0731 & 0.2524 & $-0.029^{* * *}$ & $(-6.92)$ \\
Complete & -0.0117 & 0.1489 & 0.0450 & 0.1998 & $-0.057^{* * *}$ & $(-10.95)$ \\
All & 0.0287 & 0.1844 & 0.0648 & 0.2392 & $-0.036^{* * *}$ & $(-10.88)$ \\
\hline Observations & 66281 & & 3357 & & 69638 & \\
\hline
\end{tabular}

Note: $t$ statistics in parentheses. ${ }^{*} p<0.10,{ }^{* *} p<0.05,{ }^{* * *} p<0.01$

Source: NCUA, own calculations. 


\section{Conclusions}

While IT has been playing an important role in the financial sector since the 1950s, outsourcing has been by far the preferred mode of IT provision in the recent years. The literature has identified complementary investment, network effects and compatibility issues to be crucial to a client's decision to switch the supplier of IT services. Using a large panel of micro data from US cooperative banks, we study the case of IT Outsourcing. The paper aims at three questions: What are the determinants of switching vendors, is there evidence for switching costs, and if, what is their magnitude?

Our empirical methodology consists of a two-stage model in the general class of simultaneous equation models with dummy endogenous variables. The results suggest that size, geographical location and some measures of supplier-client match are the main determinants of the switching decision. We do find significant differences between different modes of outsourcing (partial vs. complete).

In a second step we find that switching vendors has a significantly positive effect on the growth rate of expenses for professional and outside services and office operations. We conclude that switching is costly. Again we find significant differences between partial and complete outsourcing.

On average, per-period switching costs are about 3 percent of expenses. When we decompose the estimate at the mode of outsourcing and type of switching costs (direct vs. indirect), we find significant differences; our estimates range from -1.1 percent to 7.3 percent.

However, we are aware that our results are limited by an indirect measure of outsourcing fees. We plan to further investigate those issues in later versions of the paper. 


\section{References}

Bickley, J. M. (2005). “Should Credit Unions Be Taxed?” CRS Report for Congress, 97-548 E.

Borzekowski, R., and Cohen, A. (2005). "Estimating strategic complementarities in credit unions outsourcing decisions." Federal Reserve Board of Governors Working Paper.

Branch, B., and Grace, D. (2008). "Technical guide: Credit union regulation and supervision." World Council of Credit Unions.

Chen, P., and Hitt, L. (2002). "Measuring switching costs and the determinants of customer retention in Internet-enabled businesses: A study of the online brokerage industry." Information Systems Research, 13(3), 255-274.

Chen, P., and Hitt, L. M. (2006). "Information technology and switching costs." In T. Hendershott (Ed.), Information Systems Outsourcing: Enduring Themes, Global Challenges, and Process Opportunities, 437-470, Elsevier, Amsterdam.

Currie, W. (2000). "The supply-side of IT outsourcing: the trend towards mergers, acquisitions and joint ventures." Management, 30(3/4), 238-254.

Elzinga, K., and Mills, D. (1998). "Switching Costs in the Wholesale Distribution of Cigarettes." Southern Economic Journal, 65(2).

Farrell, J., and Klemperer, P. (2007). "Coordination and lock-in: Competition with switching costs and network effects." Handbook of industrial organization, 2(5), 1967-2072.

Franke, R. H. (1987). “Technological revolution and productivity decline: Computer introduction in the financial industry." Technological Forecasting and Social Change, 31(2), 143- 154.

Greenstein, S. (1993). "Did installed base give an incumbent any (measurable) advantages in federal computer procurement?" RAND Journal of Economics, 24(1), 19-39.

Grover, V., Cheon, M., and Teng, J. (1996). "The effect of service quality and partnership on the outsourcing of information systems functions." Journal of Management Information Systems, 12(4), 89-116.

Heckman, J. J. (1978). “Dummy endogenous variables in a simultaneous equation system.” Econometrica, 46(4), 931-959.

Hillman, R. J. (2005). "Issues Regarding the Tax-Exempt Status of Credit Unions." United States Government Accountability Office.

Klemperer, P. (1995). "Competition when consumers have switching costs: An overview with applications to industrial organization, macroeconomics, and international trade." The Review of Economic Studies, 62(4), 515-539.

Knittel, C. (1997). “Interstate long distance rates: search costs, switching costs, and market power." Review of Industrial Organization, 12(4), 519-536.

Knittel, C., and Stango, V. (2008). "The Productivity Benefits of IT Outsourcing." mimeo, http: //www.econ.ucdavis.edu/faculty/knittel/papers/CUproduct_latest.pdf.

Knuth, D., Morris Jr, J., and Pratt, V. (1977). "Fast pattern matching in strings." SIAM Journal on Computing, 6(2), 323-350.

Krafft, J., and Salies, E. (2008). "The diffusion of adsl and costs of switching internet providers in the broadband industry: Evidence from the french case." Research Policy, 37(4), $706-719$. 
Lacity, M. C., and Willcocks, L. P. (2001). Global Information Technology Outsourcing. John Wiley \& Sons, Chichester.

Lacity, M. C., Willcocks, L. P., and Feeny, D. (2009). “Making the outsourcing decision." In L. P. Willcocks, and M. C. Lacity (Eds.), Information Systems and Outsourcing: Studies in Theory and Practice, 212-234, Palgrave Macmillan, New York.

Loh, L., and Venkatraman, N. (1992). "Determinants of information technology outsourcing: A cross-sectional analysis." Journal of Management Information Systems, 9(1), 7-24.

Maddala, G. S. (1983). Limited-dependent and qualitative variables in econometrics. Cambridge University Press, Cambridge.

Maicas, J., Polo, Y., and Javier Sese, F. (2009). "Reducing the level of switching costs in mobile communications: The case of Mobile Number Portability." Telecommunications Policy, 33(9), $544-554$.

Miozzo, M., and Grimshaw, D. (2005). "Modularity and innovation in knowledge-intensive business services: It outsourcing in germany and the uk." Research Policy, 34(9), 1419-1439.

Muckian, M. (2002). "EDS acquisition catapults Fiserv to a new level." The Business Journal, http: //milwaukee.bizjournals.com/milwaukee/stories/2002/12/16/story6.html.

Ono, Y., and Stango, V. (2005). "Supplier switching and outsourcing." Federal Reserve Bank of Chicago Working Paper, 2005-22.

Robbins, E., and Van Walleghem, J. (2004). “Technology outsourcing: A community bank perspective." Financial Industry Perspectives, 4.

Shapiro, C., and Varian, H. (1999). Information rules: a strategic guide to the networkeconomy. Harvard Business School Press, Boston.

StataCorp. (2009). Stata Statistical Software: Release 11. StataCorp LP., College Station, TX.

von Weizsäcker, C. (1984). “The costs of substitution.” Econometrica, 52(5), 1085-1116.

Weigelt, C., and Sarkar, M. (2009). “Learning from Supply-Side Agents: The Impact of Technology Solution Providers' Experiential Diversity on Clients' Innovation Adoption." The Academy of Management Journal (AMJ), 52(1), 37-60.

Whitten, D., and Wakefield, R. (2006). "Measuring switching costs in IT outsourcing services." Journal of strategic information systems, 15(3), 219-248. 


\section{A Appendix}

Table 7: Population-Sample-Comparison

\begin{tabular}{rrrr}
\hline Year & Pop & Sample & $\%$ \\
\hline 1999 & 11,016 & 9,718 & 88.22 \\
2000 & 10,684 & 9,419 & 88.16 \\
2001 & 10,355 & 9,232 & 89.16 \\
2002 & 10,041 & 9,238 & 92.00 \\
2003 & 9,710 & 9,012 & 92.81 \\
2004 & 9,346 & 8,715 & 93.25 \\
2005 & 9,011 & 8,444 & 93.71 \\
2006 & 8,662 & 8,243 & 95.16 \\
2007 & 8,396 & 7,997 & 95.25 \\
2008 & 7,966 & 7,736 & 97.11 \\
2009 & 7,708 & 7,283 & 94.49 \\
\hline
\end{tabular}

Note: The number of $\mathrm{CUs}$ is given.

Source: NCUA, CUNA, own calculations.

Figure 10: Vendor switching (acq)

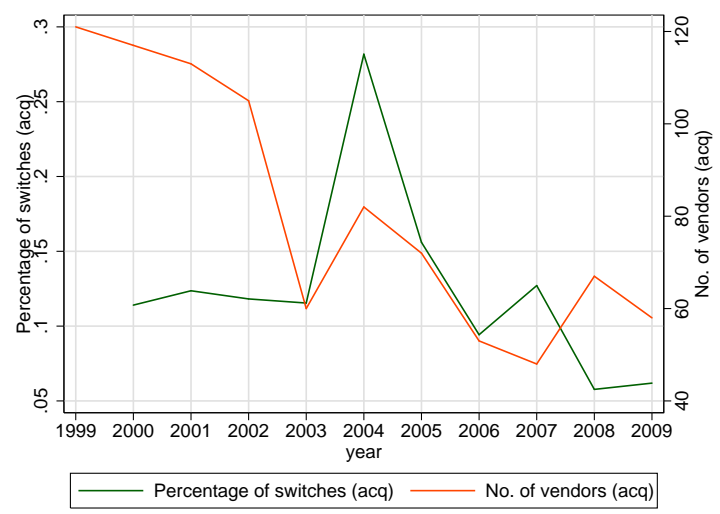

Source: NCUA, own illustration. 
Table 8: Top 3 switches

\begin{tabular}{|c|c|c|c|}
\hline Year & From & To & Number \\
\hline \multirow[t]{3}{*}{2000} & CompuSource & AFTECH & 13 \\
\hline & EDS & AFTECH & 12 \\
\hline & Fedcomp & AFTECH & 9 \\
\hline \multirow[t]{3}{*}{2001} & EDS & AFTECH & 12 \\
\hline & AFTECH & CompuSource & 9 \\
\hline & Computer Consultants & $\mathrm{CMC}$ & 9 \\
\hline \multirow[t]{3}{*}{2002} & EDS & Symitar & 7 \\
\hline & AMI & Fedcomp & 7 \\
\hline & Credit Union Online & Computer Consultants & 7 \\
\hline \multirow[t]{3}{*}{2003} & Western NY Computing & Connecticut Online & 12 \\
\hline & AFTECH & Symitar & 5 \\
\hline & Fedcomp & FITECH & 5 \\
\hline \multirow[t]{3}{*}{2004} & Fedcomp & Financial Data Corp & 10 \\
\hline & AFTECH & Symitar & 8 \\
\hline & Computer Consultants & Fedcomp & 6 \\
\hline \multirow[t]{3}{*}{2005} & Financial Software Group & Fedcomp & 10 \\
\hline & Computer Consultants & Fedcomp & 10 \\
\hline & CU Source & Harland & 7 \\
\hline \multirow[t]{3}{*}{2006} & Fedcomp & Fidelity & 12 \\
\hline & Real Time Data Management & CU Nation & 8 \\
\hline & CU Source & Harland & 7 \\
\hline \multirow[t]{3}{*}{2007} & Fidelity & Fedcomp & 19 \\
\hline & One's Technology & Harland & 11 \\
\hline & Hawaii Impulse Systems & EPL & 11 \\
\hline \multirow[t]{3}{*}{2008} & Open Solutions & Harland (Symitar) & 9 \\
\hline & Fidelity & Fedcomp & 9 \\
\hline & Open Solutions & CU Answers & 6 \\
\hline \multirow[t]{3}{*}{2009} & Open Solutions & Harland (Symitar) & 11 \\
\hline & CU Nation & Real Time Data Management & 5 \\
\hline & Open Solutions & Share One & 4 \\
\hline
\end{tabular}

Source: NCUA, own calculations. 
Table 9: CU services

\begin{tabular}{|c|c|}
\hline Service & Description \\
\hline Account Aggregation & $\begin{array}{l}\text { Service to present account information from may websites in a con- } \\
\text { solidated format }\end{array}$ \\
\hline \multicolumn{2}{|l|}{ Account Balance Inquiry } \\
\hline Bill Payment & Service to pay bills issued by third parties \\
\hline \multicolumn{2}{|l|}{ Download account History } \\
\hline Electronic Cash & $\begin{array}{l}\text { Service to transfer monetary values that can be stored on a variety } \\
\text { of media, including a PC, plastic card, or other device that has a } \\
\text { computer chip or magnetic strip }\end{array}$ \\
\hline Electronic Signature & Service to verify, and certify related electronic signature \\
\hline E-Statements & $\begin{array}{l}\text { Service where members can choose to receive their periodic state- } \\
\text { ments electronically rather than receiving a paper statement in the } \\
\text { mail. }\end{array}$ \\
\hline Internet Access Services & Service to provide members with access to the internet \\
\hline \multicolumn{2}{|r|}{ service to provide memoers witn access to the mternet } \\
\hline MA: ATM & Member access via ATMs \\
\hline MA: Audio Response & Member access via phone-based audio response \\
\hline MA: Home banking - Web & Member access via the Internet \\
\hline MA: Kiosk & Member access via kiosks \\
\hline MA: Wireless & Member access via cell phones, PDAs, etc. \\
\hline MA: Home banking - PC & Member access via direct dial-up/PCs \\
\hline \multicolumn{2}{|l|}{ Merchandise Purchase } \\
\hline New Loan & $\begin{array}{l}\text { Service that allows members to access and submit an application } \\
\text { electronically via the internet }\end{array}$ \\
\hline New Share Account & $\begin{array}{l}\text { Service that allows members to access and submit an application } \\
\text { electronically via the internet }\end{array}$ \\
\hline \multicolumn{2}{|l|}{ Share Draft Orders } \\
\hline \multicolumn{2}{|l|}{ Share Account Transfers } \\
\hline View Account History & \\
\hline
\end{tabular}

Source: NCUA, Weigelt and Sarkar (2009). 
Table 10: Vendors

\begin{tabular}{|c|c|c|}
\hline \multicolumn{3}{|c|}{ Vendor name } \\
\hline Advanced Management Info. Systems & Data Tech Services, Inc. & Midwest Marketing \\
\hline Alltel & Datamatic & Mize Houser \& Company \\
\hline Ams & Datex & Modern Data Management \\
\hline American Business Computers & Digital Processing Subsystems & Myrick Computer Services, Inc. \\
\hline Ami, Inc. & Ebank Systems, Inc & Nc State Employees' Credit Union \\
\hline Amis & Ed Ouellette & Ncr Corporation \\
\hline Apex Data Systems, Inc. & Edcomp & Nilco, Inc \\
\hline Apple Federal Credit Union & Efficiency Works, Inc. & North Carolina State Employeess Cre \\
\hline Area Financial Services & Eds & Northern Data Systems \\
\hline Assoc. Of Community Credit Unions & Electronic Recordkeeping Services & One's Technologies \\
\hline Atcu & Emphacys Software Inc & Open Solutions, Inc \\
\hline Automated Financial Technology Inc. & Empire Corp & Pa Credit Union Association \\
\hline Automated Systems Management, Inc. & Enhanced Software Products, Inc. & Pacific Business Services \\
\hline Banctec, Inc. & Epl & Pacul \\
\hline Bcg,Inc. & Evergent Solutions, Llp & Palos Community Hospital \\
\hline Beycaldwell Group & Fedcomp, Inc. & Paragon Services Inc \\
\hline Beysch Consulting Group & Fidelity & Peerless Group \\
\hline Bsa Turnkey Corp. & Fifs & Pennsylvania Credit Union League \\
\hline C T I & Financial Consultants International & Perform, Inc. \\
\hline C.U. Processing, Inc. & Financial Data Corporation & Premier Systems, Inc. \\
\hline C.U. Services, Inc. & Financial Services Group & Prodata, Inc. \\
\hline C.U. Solutions, Inc. (Sunbelt) & Financial Software Group & Protestant Data \\
\hline $\mathrm{Cbs}$ & Fincentric & Psa \\
\hline Charles Davis Cpa & First Ascent Investments, Inc. & R.C. Olmstead, Inc. \\
\hline Cherry Creek Technologies & Cusa & Re:Member Data Services, Inc. \\
\hline Computer Marketing Corp. & Fitech Systems & Real Time Data Management Services \\
\hline Commercial Business Systems, Inc. & Fsg Computer Software & Risk Management \\
\hline Community First Credit Union & Gds & Roop Services \\
\hline Compuserve & Gem Software & Ryli Software Associates \\
\hline Compusource Systems, Inc. & Gfc Data Systems & Share One, Inc \\
\hline Computek & Gulf Data Systems & Sharetec Systems, Inc \\
\hline Computer Business Systems & Gunther Computer Systems, Inc. & Smart Solution \\
\hline Connecticut On-Line & Haggarty Associates & Sos Computer Systems, Inc. \\
\hline Cpi Proservices, Inc & Harland Financial Solutions & Southern Regional Data Corporation \\
\hline Cred-U-Comp, Inc. & Hattan Enterprise Union 3 & State Employees' Credit Union \\
\hline Credimax & Hawaii Impulse Systems, Inc. & Stl Solutions, Ltd. \\
\hline Credit Union Consultants, Inc. & Helvetia Del Caribe, Inc. & Superior Services, Inc. \\
\hline Credit Union Data Processing, Inc. & Heritage Credit Union & Symitar Systems \\
\hline Credit Union Management System & Houston Energy Credit Union & Syntropy, Inc. \\
\hline Credit Union Online, Inc. & Huron River Area Credit Union & Systronics, Llc \\
\hline $\mathrm{Cu}$ Accounting & Icsi & T.S.I. \\
\hline $\mathrm{Cu}$ Data & Infoware & Temenos Usa \\
\hline $\mathrm{Cu}$ Interface & Innovative Technology, Inc. & Terra Firma Software, Inc. \\
\hline Cu Nation & Int'L Software Systems, Inc. & Total/1 Corporation \\
\hline $\mathrm{Cu}$ Vision Technologies & International Software Systems, Inc & Tracking Services, Inc. \\
\hline $\mathrm{Cu}^{*}$ Answers & Ips, Inc. & Trinergy \\
\hline $\mathrm{Cu}^{*}$ Northwest & Iss & United Solutions Company \\
\hline $\mathrm{Cu}{ }^{*}$ South & Symitar Systems, Inc. & Valtek Emp. Cu \\
\hline Cu-Centric & Leber Services & Vermont Heritage Financial Group \\
\hline Cuc, Inc & Liberty & Versyss \\
\hline Cufas & Link $21 \mathrm{Pc} \mathrm{Cu}$ Software & Vision \\
\hline Cumas (John J. Shutt) & Listerhill Credit Union & Vision Xxi \\
\hline Cuna & Lufthansa System House & Wescom Resources Group \\
\hline C.U.S. & Maine Credit Union League & West Shore Community College \\
\hline Cusoft & Mcba & Western New York Computing Systems \\
\hline Cusource, Inc. & Mecul & Williams \& Associates \\
\hline Custom/Data & Meints Computing Services & Worldwide Interactive Services, Inc \\
\hline Data Basics & Member Computer Solutions & Worthy Computers \\
\hline Data Management Inc. & Member Driven Technologies (Episys) & Young's Software \\
\hline Data Services, Inc. & Mid Michigan Cuso & \\
\hline
\end{tabular}

Source: NCUA. 
Table 11: M\&A in the vendor market

\begin{tabular}{|c|c|c|c|}
\hline Year & Vendor & Acquired by/Related to & Renamed to \\
\hline$?$ & $\begin{array}{l}\text { CUSERVE } \\
\text { CU Manager } \\
\text { Aftech } \\
\text { Galaxy } \\
\text { Summit } \\
\text { Users } \\
\text { XP Systems } \\
\text { Synergent Corp. }\end{array}$ & $\begin{array}{l}\text { Harland Financial Solutions } \\
\text { Real Time Data Management } \\
\text { Fiserv } \\
\text { Fiserv } \\
\text { Fiserv } \\
\text { Fiserv } \\
\text { Fiserv } \\
\text { Maine Credit Union League }\end{array}$ & \\
\hline 1994 & $\begin{array}{l}\text { Bradford-Scott Data Corporation } \\
\text { Data Systems of Texas } \\
\text { GBS Corp }\end{array}$ & $\begin{array}{l}\text { Sharetec Systems } \\
\text { Sharetec Systems } \\
\text { Sharetec Systems }\end{array}$ & \\
\hline 1997 & XP Systems & Users & UXP Corp. \\
\hline 1998 & $\begin{array}{l}\text { CUSA } \\
\text { Peerless }\end{array}$ & $\begin{array}{l}\text { Fiserv } \\
\text { Jack Henry \& Associates }\end{array}$ & \\
\hline 1999 & $\begin{array}{l}\text { Ultradata } \\
\text { Modern Computer Systems }\end{array}$ & $\begin{array}{l}\text { Concentrex } \\
\text { Concentrex }\end{array}$ & \\
\hline 2000 & $\begin{array}{l}\text { CU Processing } \\
\text { Concentrex } \\
\text { Symitar }\end{array}$ & $\begin{array}{l}\text { CGI } \\
\text { Harland Financial Solutions } \\
\text { Jack Henry \& Associates }\end{array}$ & \\
\hline 2002 & $\begin{array}{l}\text { Aurum Technology } \\
\text { Prodata }\end{array}$ & $\begin{array}{l}\text { EDS } \\
\text { Premier } \\
\end{array}$ & \\
\hline 2003 & $\begin{array}{l}\text { EDS } \\
\text { Computer Consultants } \\
\text { FiTech Liberty } \\
\text { Wesco } \\
\text { Premier } \\
\text { Alltel } \\
\text { Evergent }\end{array}$ & $\begin{array}{l}\text { Fiserv } \\
\text { Aurum Technology } \\
\text { Open Solutions } \\
\text { Harland Financial Solutions } \\
\text { Fidelity } \\
\text { Fedcomp }\end{array}$ & $\begin{array}{l}\text { Integrasys } \\
\text { CU*Answers }\end{array}$ \\
\hline 2004 & $\begin{array}{l}\text { Aurum Technology Inc } \\
\text { CU Solutions } \\
\text { Re:Member Data Services } \\
\text { Hawaii Impulse Systems } \\
\text { Western New York Computing Systems }\end{array}$ & $\begin{array}{l}\text { Fidelity } \\
\text { Symitar } \\
\text { Open Solutions } \\
\text { Open Solutions } \\
\text { Synergy }\end{array}$ & \\
\hline 2005 & $\begin{array}{l}\text { SO Systems } \\
\text { CGI }\end{array}$ & $\begin{array}{l}\text { Open Solutions } \\
\text { Open Solutions }\end{array}$ & \\
\hline 2006 & Evergent Solutions & & Bankrupcty \\
\hline 2007 & ONE's Technology & Harland Financial Soultions & \\
\hline
\end{tabular}

Source: Robbins and Van Walleghem (2004), SEC filings, corporate annual reports and webpages. 